Génét. Sél. Evol., 1987, 19 (3), 297-306

\title{
Low frequency of inversion-carrying chromosomes in a population of Drosophila melanogaster from a cellar habitat
}

\author{
Ana GONZÁLEZ and J.L. MÉNSUA \\ Departamento de Genética, Facultad de Ciencias Biológicas, \\ Universidad de Valencia, Dr. Moliner, 50, Burjassot, Valencia, Spain
}

\begin{abstract}
Summary
The inversions of the 3 rd chromosome are studied in 2 neighbouring populations of Drosophila melanogaster, one from a cellar habitat, and the other from a vineyard outside.

The cellar population shows a lower frequency of chromosomes with inversions than the outside population. In the cellar, the average homozygote viability for inversion-carrying chromosomes is smaller than for inversion-free chromosomes. In the vineyard population there are no differences between the 2 types of chromosomes.
\end{abstract}

Key words : Drosophila melanogaster, inversion, adaptability, viability, cellar.

\begin{abstract}
Résumé
Faible fréquence de chromosomes avec inversion dans une population de Drosophila melanogaster d'un habitat de cave
\end{abstract}

On a étudié les inversions du $3^{e}$ chromosome de 2 populations voisines de Drosophila melanogaster, l'une d'un habitat de cave et l'autre d'un vignoble.

La population de la cave présente une plus faible fréquence de chromosomes avec inversion que la population extérieure. En cave, les chromosomes avec inversion sont moins viables, à l'état homozygote, que les chromosomes sans inversion. Dans la population extérieure, il n'existe pas de différence de viabilité entre les 2 types de chromosomes.

Mots clés : Drosophila melanogaster, inversion, adaptabilité, viabilité, cave.

\section{Introduction}

Drosophila melanogaster is a chromosomally polymorphic species, as has been confirmed in various natural populations by many workers in this field (ASHBURNER \& Lemeunier, 1976 ; ChoI, 1977 ; Mettler et al., 1977 ; InOue \& Watanabe, 1979 ; Paik, 1979 ; Zacharopoulou \& Pelecanos, 1980 ; Knibb et al., 1981, Inoue et al., 
1984). Particular studies in this species suggest that the presence or absence of chromosomal inversions might be involved in the adaptability of populations to given environments (KNIBB et al., 1981), and include associations of inversion frequencies in some natural populations with food type, size of sperm load in females, yearly seasons or wing-load index and flying ability at low temperatures (STALKER, 1976;1980). However, there have been few studies on inversion polymorphism in natural populations from specific ecological situations or habitats.

Cellars constitute a peculiar environment for Drosophila. The factors which constitute this environment are diverse and complex : a high concentration of alcohol (especially ethanol), a greater uniformity of temperature and humidity throughout the year, limited space, scarcity of light, etc. Drosophila melanogaster, which is the most abundant Drosophila species in this habitat (MOnClus \& PrEvosTI, 1978), must adapt to all these factors.

This study attempts to determine the nature of the chromosomal polymorphism in a cellar population of Drosophila melanogaster, and in a population from outside the cellar, and to determine whether the presence or absence of inversions might be important in the adaptation of $D$. melanogaster to the cellar habitat. The fitness of chromosomes was estimated by measuring their viabilities.

\section{Material and methods}

At the end of October 1979 simultaneous captures of Drosophila melanogaster were made in 2 relatively distinct habitats near Requena (Valencia-Spain) : a cellar and an outside location (vineyard) about $4 \mathrm{~km}$ from the cellar.

On the days of capture the temperatures in the vineyard reached minima of $3{ }^{\circ} \mathrm{C}$ to $4^{\circ} \mathrm{C}$ and maxima of $7^{\circ} \mathrm{C}$ to $8^{\circ} \mathrm{C}$. In the cellar the temperatures varied between $11{ }^{\circ} \mathrm{C}$ and $14{ }^{\circ} \mathrm{C}$. The relative humidity was 55-58 p. 100 in the vineyard and 51-53 p. 100 in the cellar. The flies were aspirated individually by suction into glass vials, and then transferred into culture bottles.

\section{A. Extraction and maintenance of third chromosomes}

Each male captured in the wild, or one single son from each female inseminated in the wild and isolated at the place of capture, was crossed with 3 virgin $\mathrm{Ubx}^{130} \mathrm{es} / \mathrm{CSb}$ females (Ubx : ultrabithorax, which is included in $\operatorname{In}(3 L R) T M 2$ ). In the following generation a single phenotypically Ubx male from the progeny of each cross was again crossed with three $\mathrm{Ubx} / \mathrm{Sb}$ females.

In order to maintain the chromosomes as lines, in each generation $\mathrm{Ubx} /+\mathrm{i}$ males ( $\mathrm{i}=\mathrm{n}^{\circ}$ of line) were crossed with virgin Ubx/CSb females. Maintaining the chromosomes in this way allowed first of all an estimation of the relative viabilities of chromosome groups at given times and secondly, overcomes the problem that when stocks are maintained in cage populations (INOUE, 1979) or as isolines (INOUE, quoted by KNIBB et al. , 1981), the cosmopolitan inversions tend to be eliminated after several generations. 


\section{B. Estimation of relative viability}

The homozygote and heterozygote relative viabilities of the $3 \mathrm{rd}$ chromosome were estimated as follows : crosses were made between $4 \mathrm{Ubx} /+\mathrm{i}$ females and $4 \mathrm{Ubx} /+\mathrm{i}$ males with 2 simultaneous replications in each chromosome line, where "i" indicates line number. In the offspring, $\mathrm{Ubx} /+\mathrm{i}$ flies segregate at an expected ratio of $2: 1$. The relative viabilities of random heterozygotes were estimated in a way similar to the above, combining 2 successively numbered lines, i.e., $\mathrm{Ubx} /+\mathrm{i} \times \mathrm{Ubx} / \mathrm{i}+1$ in order to secure random combination of different chromosome lines. In both cases, 4 days after the crosses were made, all 8 flies in a vial were transferred to a second vial. Four days after the transfer, all flies were discarded. In both the original and the transferred vials, all flies were counted 3 times until the 18th day after the cross or transfer was made. Ubx flies and wild type flies from the pair of vials were respectively pooled and considered as a single observation. Relative viability was expressed as the ratio of (the number of wild type progeny flies) to (the number of Ubx progeny flies +1 ) (cf. HALDANE, 1956).

\section{Detection of inversions}

Cytological examination of the salivary chromosomes in the balanced lines was difficult because of the presence of Ubx chromosomes. Two Ubx/+i males were therefore crossed whith 3 virgin "rucuca" females (a strain which is homozygous for the standard arrangement). Two rucuca/ $+\mathrm{i}$ males of the $F_{1}$ were then crossed with 3 virgin "rucuca" females. Third instar larvae were collected from the progeny of this latter cross, and their salivary glands extracted. Lactic-acetic orcein $(80 / 20)$ for $45 \mathrm{~min}$ was used to stain the chromosomes, followed by the usual squashing technique. Eight preparations of each chromosome line were observed and a given chromosome line was considered not to carry inversions when no inversions appeared in any of the 8 preparations. The theoretical probability of not choosing a heterozygous "rucuca" larva when observing the 8 preparations is $(1 / 2)^{8}=0.0039$. The nomenclature of already-known inversions is that of LiNDSLEY \& GRELL (1972). The inversion break-points were established by comparing photographs with photographic representations of BRIDGES' (1935) standard maps (LEFEVRE, 1976).

\section{Results}

In a previous study (Gonzalez, 1985), 155 cellar and 145 vineyard third chromosomes were analysed for viability. In the cellar, the average homozygote viability, computed on the basis of an average heterozygote viability of 1.000 , was $0.401 \pm 0.025$ if lethal lines were included and $0.519 \pm 0.025$ if they were excluded. In the vineyard, the average homozygote viability was $0.367 \pm 0.025$ including lethal lines and $0.493 \pm$ 0.026 excluding them. In the present study 161 third chromosomes out of the 300 of the previous study have been analysed cytologically for inversions (86 from the cellar population and 75 from the vineyard). Of these chromosomes, 78 were lethal carriers (38 from the cellar and 40 from the vineyard). 


\section{A. Description of inversions}

The inversions found in the 2 populations under consideration were classified according to the categories adopted by INOUE \& WATANABE (1979), which are modifications of those of METTLER et al. (1977).

"Common cosmopolitan inversions" are the most frequent world-wide inversions and occur on every major autosomal arm.

"Rare cosmopolitan inversions" are distributed world-wide but at a lower frequency than the common cosmopolitan inversions.

"Recurrent endemic inversions" are restricted to certain regions.

"Unique endemic inversions" are usually observed in a single individual or its brood from a single population, and never found in a different population.

Five different inversions were found on the 3 rd chromosomes from the populations studied, as detailed below. Of these, 4 were found on the $3 \mathrm{R}$ and one the $3 \mathrm{~L}$ arm :

- In(3L)P 63C-75E Paracentric Common cosmopolitan

- In(3R)P 89C-96A Paracentric Common cosmopolitan

- In(3R)C 92D-100F Paracentric Rare cosmopolitan

- In(3R)Mo 93D-98F Paracentric Rare cosmopolitan

- In(3R)BoI 86E-92F Paracentric Unique endemic

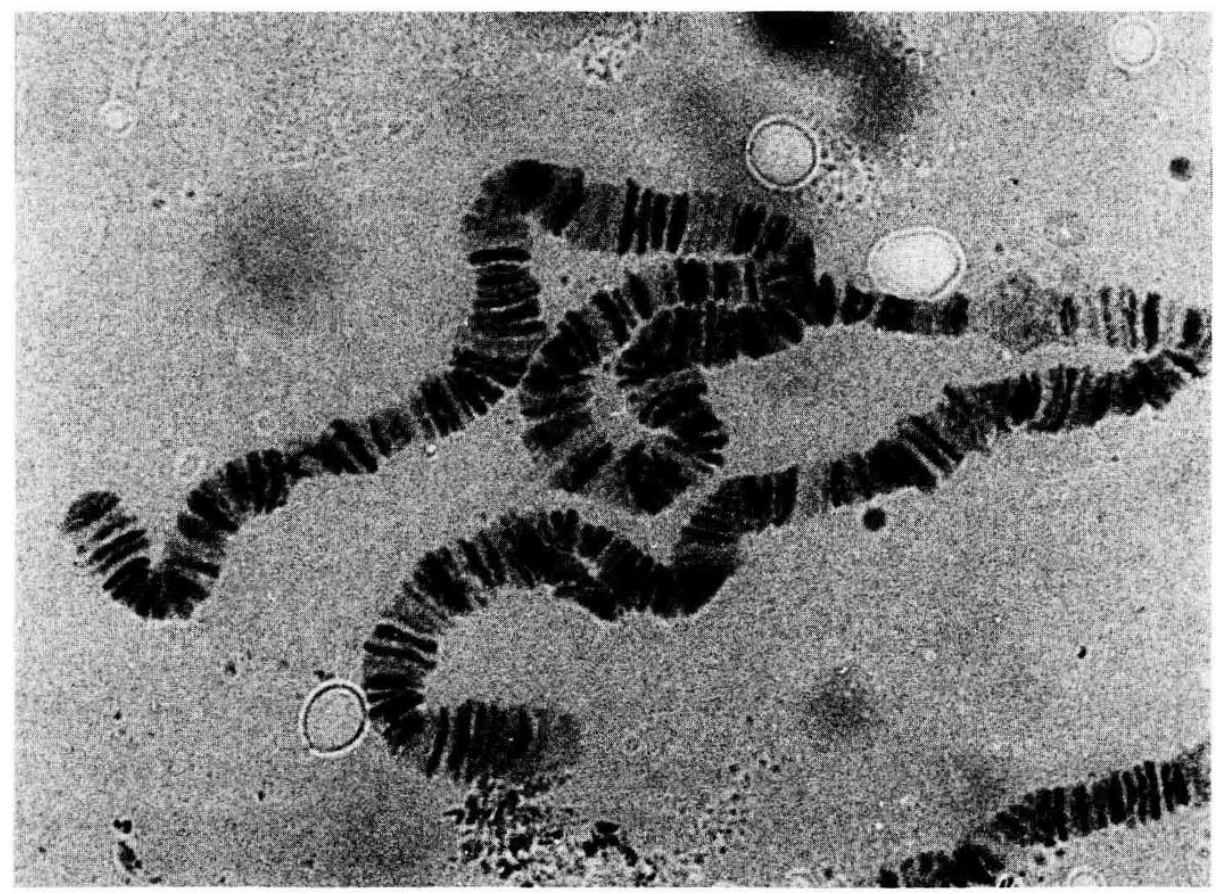

FIG. 1

Inversion BoI (86E - 92F). A previously undescribed inversion, found in a cellar population. 

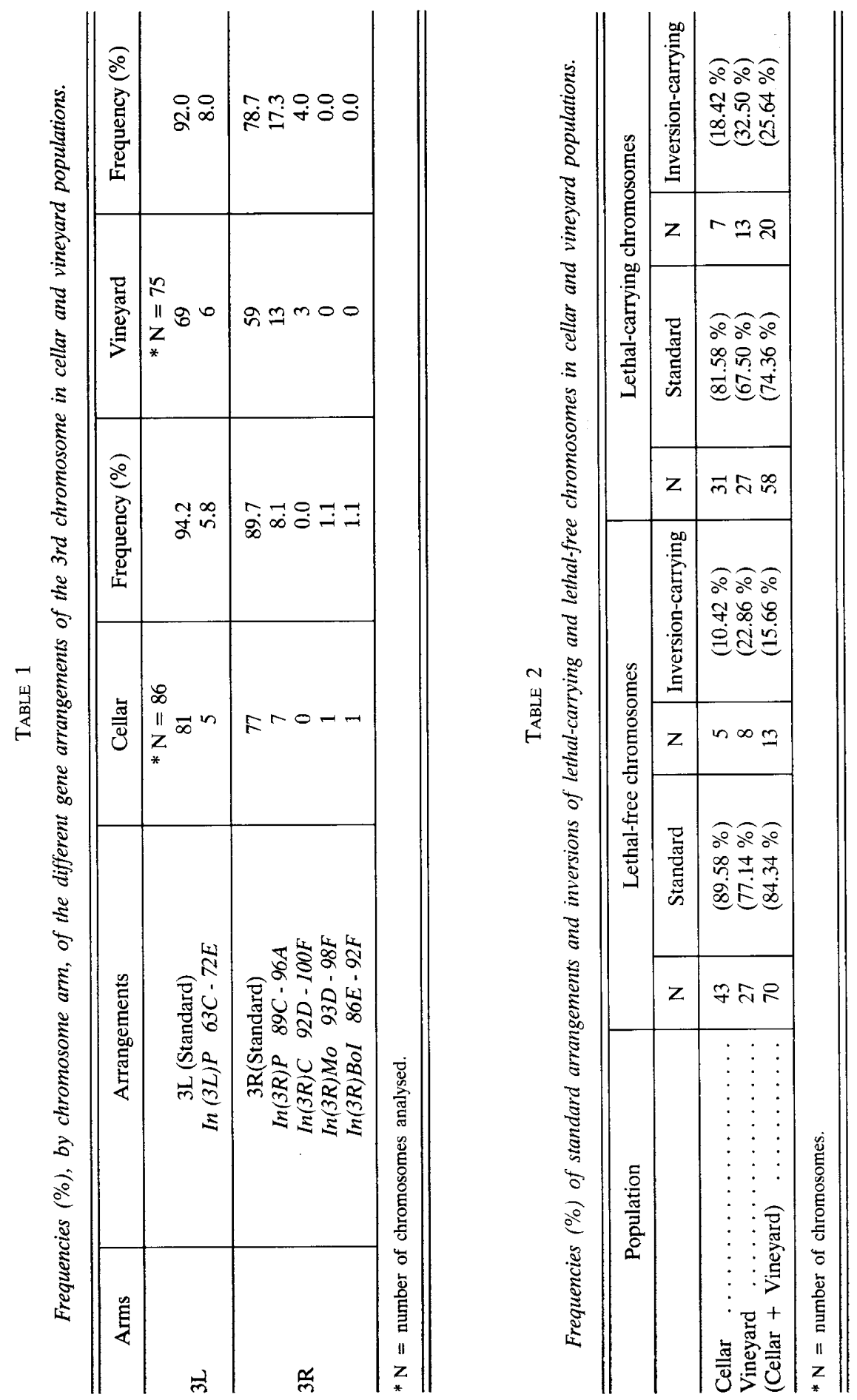
Only 3 isolated chromosomes had more than one inversion, and each of these had both $\operatorname{In}(3 L) P$ and $\operatorname{In}(3 R) P$, indicating no significant linkage disequilibrium either overall, or within the 2 populations. The 3 chromosomes with these inversions linked were lethal carriers, and by allelism analysis it was confirmed that they were not allelic lethals.

It will be seen that the majority of inversions found in these populations are cosmopolitan. However, a unique endemic inversion on the $3 \mathrm{R}$ arm has been found with breakpoints at $86 \mathrm{E}-92 \mathrm{~F}$ (fig. 1).

\section{B. Frequencies of the inversions}

The number of chromosomes examined and the frequencies of the various gene arrangements are given in table 1 . The results indicate that although $\operatorname{In}(3 L) P$ and $\operatorname{In}(3 R) P$ each occur at a higher frequency in the vineyard than in the cellar population, these differences are not statistically significant. However, when all inversions are pooled there is a significant difference between populations.

In the cellar population 12 inversion-carrying chromosomes were found $(13.95$ p. $100 \pm 2.73)$ and 21 in the vineyard population $(28.00$ p. $100 \pm 3.53)$. The difference between the 2 frequencies is significant at the 0.05 level $(\mathrm{t}=2.21, \mathrm{df}=159, \mathrm{p}<0.05)$.

\section{Association of lethals and inversions}

Table 2 shows the frequencies (p. 100) of standard and inversion arrangements present in the lethal-carrying and lethal-free chromosomes from the cellar and vineyard populations.

We tested for possible associations of lethals with inversions before and after pooling the 2 populations samples. In both cases a slightly higher frequency of inversions was observed in the lethal-carrying chromosomes than in the lethal-free chromosomes. However, in no case was the association significant.

\section{Relative viabilities of third chromosomes in homozygotes and heterozygotes}

Average homozygote viability for inversion-free chromosomes from the cellar was significantly greater than that of the cellar inversion-carrying chromosomes, and those of the vineyard inversion-free or inversion-carrying chromosomes, whether or not lethals were considered (table 3).

While sampling error may have contributed to these results it should be noted that there were no significant differences between the average homozygote viabilities of the chromosomal sample analysed in the present work ( 86 chromosomes including the lethals and 48 excluding them) and the average homozygote viabilities from a greater chromosomal sample (155 chromosomes including the lethals and 117 excluding them) estimated previously (GONZALEZ, 1985).

The average viabilities of heterozygous homokaryotypes (STi/STj) and heterokaryotypes (ST/IN) of the two populations were also compared (table 4). There were no significant differences either in the cellar or in the vineyard populations. 


\section{TABLE 3}

Average homozygote viabilities and their standard errors for the $3 r d$ chromosomes with and without inversions, in the cellar and vineyard populations.

(A) Including lethal-carrying chromosomes. (B) Excluding lethal-carrying chromosomes.

\begin{tabular}{|c|c|c|c|c|}
\hline (A) Chromosomes & \multicolumn{4}{|c|}{ Population } \\
\hline & \multicolumn{2}{|r|}{ Cellar } & \multicolumn{2}{|r|}{ Vineyard } \\
\hline & $\mathrm{N}$ & Average viability & $\mathrm{N}$ & Average viability \\
\hline \multirow[t]{2}{*}{$\begin{array}{l}\text { Inversion-carrying } \\
\text { Inversion-free (ST) }\end{array}$} & $\begin{array}{l}12 \\
74\end{array}$ & $\begin{array}{l}0.157 \pm 0.058(\mathrm{a}) \\
0.383 \pm 0.042(\mathrm{c})\end{array}$ & $\begin{array}{l}21 \\
54\end{array}$ & $\begin{array}{l}0.213 \pm 0.066(\mathrm{~b}) \\
0.225 \pm 0.035(\mathrm{~d})\end{array}$ \\
\hline & \multicolumn{4}{|c|}{ (a) $-(\mathrm{c})^{* *} ;(\mathrm{b})-(\mathrm{c})^{*} ;(\mathrm{c})-(\mathrm{d})^{* *}$} \\
\hline (B) Chromosomes & \multicolumn{4}{|c|}{ Population } \\
\hline \multirow{4}{*}{$\begin{array}{l}\text { Inversion-carrying } \\
\text { Inversion-free (ST) }\end{array}$} & \multicolumn{2}{|r|}{ Cellar } & \multicolumn{2}{|r|}{ Vineyard } \\
\hline & $\mathrm{N}$ & Average viability & $\mathrm{N}$ & Average viability \\
\hline & $\begin{array}{r}5 \\
43\end{array}$ & $\begin{array}{l}0.330 \pm 0.097\left(\mathrm{a}^{\prime}\right) \\
0.630 \pm 0.040\left(\mathrm{c}^{\prime}\right)\end{array}$ & $\begin{array}{r}8 \\
27\end{array}$ & $\begin{array}{l}0.425 \pm 0.061\left(b^{\prime}\right) \\
0.403 \pm 0.051\left(d^{\prime}\right)\end{array}$ \\
\hline & \multicolumn{4}{|c|}{$\left(a^{\prime}\right)-\left(c^{\prime}\right)^{* *} ;\left(b^{\prime}\right)-\left(c^{\prime}\right)^{* *} ;\left(c^{\prime}\right)-\left(d^{\prime}\right)^{* *}$} \\
\hline
\end{tabular}

TABLE 4

Average heterozygote viabilities for the 3rd chromosome, of homokaryotype $\left(S T_{i} / S T_{j}\right)$ and heterokaryotype (ST/In) genotypes, in the cellar and vineyard populations.

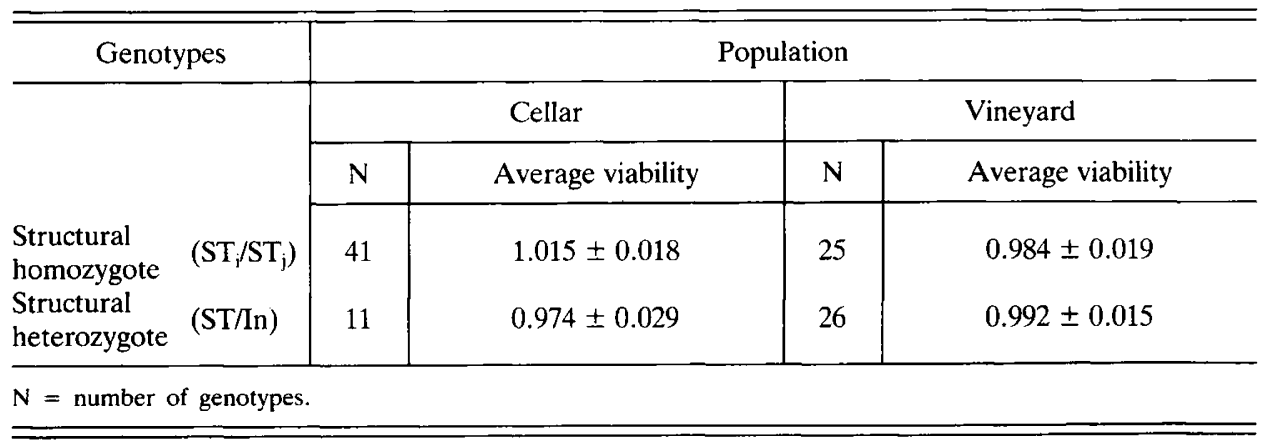




\section{Discussion and conclusions}

The cosmopolitan inversions of the 3rd chromosome of Drosophila melanogaster in the cellar population of the present study show frequencies which lie inside the range found in a survey of 12 cellars in different Spanish localities : $\operatorname{In}(3 L) R \approx 0.6$ p. 100 -9.5 p. $100 ; \operatorname{In}(3 R) P \approx 1.5$ p. $100-12$ p. $100 ; \operatorname{In}(3 R) C \approx 0$ p. $100-6.4$ p. 100 (PREVOSTI, personal communication) ; this survey also indicated the presence of endemic inversions in the majority of the cellars studied. In the cellar studied here, an endemic inversion, not previously described, has been found $[\operatorname{In}(3 R) B o I ; 86 E-92 F]$, and in a study made with flies from the same cellar, maintained in the laboratory, another endemic inversion, $[\operatorname{In}(3 R) B o I I ; 87 C-93 D]$, has also been found which had not been described previously (NAJERA, 1985). The data regarding the total frequency of inversions of the third chromosome indicate a lower frequency in the cellar than in the vineyard population.

It should be borne in mind that although the sample sizes are not especially large, they were of the same order in both populations. The sizes are sufficiently great to detect differences between inversion-free and inversion-carrying chromosomes with a probability of $70 \mathrm{p}$. 100 at the 0.05 level of significance. It may be thought that drift processes play an important role in determining the frequencies of inversion-carrying chromosomes. However, the effective sizes estimated in both populations were $\mathrm{Ne} \approx$ 8000 for the cellar and $\mathrm{Ne} \approx 12000$ for the vineyard (Gonzalez, 1985). These values indicate that both populations are relatively large and therefore the effect of drift in them should theoretically be small.

It is considered that the factors associated with the cellar habitat create different adaptive responses in Drosophila melanogaster from those produced by the vineyard habitat, and that the inversions seem to be involved in some way in these responses. STALKer $(1976 ; 1980)$ found an association, in Drosophila melanogaster, between different ecological niches (i.e. different food resources) and particular inversions. The presence of alcohol (principally ethanol) at high concentrations is one of the most salient characteristics of the cellar. However, alcohol is not the only characteristic component of wine and there are related products present in the cellars that can be used as food for the flies (Monclus \& Prevosti, 1978).

The availability of ecological niches which can be used by Drosophila is lower in cellars than in vineyards, although MCKEnZIE \& PARsons (1974) detected microdifferentiation in a cellar population of Drosophila melanogaster. This, according to DA CunHA \& DobHansky (1954), would imply less chromosomal polymorphism in the cellar, and consequently, a lower level of structural heterozygosity in these populations.

The data on chromosome viability from cellar and vineyard seem to support the idea that the absence of inversions could be important in the adaptation of Drosophila melanogaster to the cellar habitat. It is observed on the one hand, that in neither of the 2 populations are there differences in the average heterozygote viabilities of genotypes which are structurally homozygous and heterozygous. On the other, the average homozygous viabilities of inversion-free chromosomes from the cellar are greater than those of cellar inversion-carrying chromosomes and both types of chromosomes from the vineyard population. It must be pointed out, though, that laboratory conditions are never similar to nature. The viabilities of the chromosomes of both populations were analysed under the same conditions and it has been assumed that the fitness estimated 
can reflect the relative behaviour of the chromosomes in each of their respective habitats, without taking into account the possible distortions due to genotype-environment interactions (TACHIDA \& MUKAI, 1985).

INOUE (1979) observed, during the maintenance of wild caught Drosophila melanogaster as laboratory populations, that the total frequency of all inversions as well as the frequency of each inversion decreased, and that the inversion-carrying chromosomes were disadvantageous compared with the standard chromosomes. WATANABE et al. (1976), analysing chromosomes of a cage population, found that the inversion-free lines had greater homozygote viability than those with inversions, but that the heterozygote viability was similar for both chromosome types. Thus, the behaviour of the chromosomes from the cellar is analogous to that of the chromosomes from these cage populations.

However, in other natural populations of Drosophila melanogaster, it seems that the standard and inversion-carrying chromosomes do not differ in their relative viabilities either in the homozygous or the heterozygous state (MuKaI \& YamaguchI, 1974; KusaKabe \& MukaI, 1984 ; TACHIDA \& MuKaI, 1985). This behaviour, then, is similar to that of the chromosomes from our vineyard population.

In accordance with this, it would be possible to suppose that the inversions were introduced into the cellars from outside and here, as homozygotes, they were being selected against every generation. Theoretically, then, the cellar populations should tend towards monomorphism, but in practice this does not happen. Perhaps this is because the cellar is not a totally isolated population and, particularly at the grape harvest (end of September), there is a migration of flies from outside.

The low frequency of inversion-carrying chromosomes in the cellar compared to the vineyard population could also be influenced by the differing behaviour of the 2 populations in response to seasonal changes. Because of the semi-open habitat of the cellar, changes in the weather could affect cellar populations less than those which live outside. Particular populations of Drosophila melanogaster show seasonal changes in the frequencies of standard sequence chromosomes (STALKER, 1980 ; ZaCHAROPOUPOLOU \& Pelecanos, 1980) : at the beginning of spring they have relatively higher frequencies of standard arrangements, reflecting a pattern of selection favoring such arrangements during the coldest months of the year. Such high frequencies appear reduced by selection during the warm months, and are restored again in the following winter. These seasonal changes are shown by populations where there are sharp changes in temperature between winter and summer (STALKER, 1980), which is a similar situation to that of the vineyard population. Our collections were made at the end of October, a time at which, theoretically, there should be relatively high frequencies of inversion-carrying chromosomes. If the seasonal changes affect the vineyard population, but not that of the cellar, then the results obtained could be a reflection of this.

Regarding association of inversions and lethals, the results of this study show that inversion-carrying chromosomes have slightly higher, albeit not significantly so, frequencies of lethals than the standard chromosomes. Other studies in some populations of Drosophila melanogaster show clearly that the inversion-carrying chromosomes carry lethals more frequently than inversion-free chromosomes (WATANABE \& WATANABE, 1973 ; Mukai \& Yamaguchi, 1974 ; Watanabe et al., 1976 ; but see Watanabe \& YAMAZAKI, 1976). It is possible that our results of no association between lethals and inversions might be due to a not too large sampling number.

Received July 24, 1986.

Accepted December 2, 1986. 


\section{References}

Ashburner M., Lemeunier F., 1976. Relationships within the melanogaster species subgroup of the genus Drosophila (Sophophora). I. Inversion polymorphisms in Drosophila melanogaster and Drosophila simulans. Proc. Roy. Soc., Lond. B., 193, 137-157.

BRIDGES C.B., 1935. Salivary chromosome maps with a key to the banding of the chromosomes of Drosophila melanogaster. J. Hered., 26, 60-64.

CHог Y., 1977. Chromosomal polymorphism in a Korean natural population of Drosophila melanogaster. Genetica, 47, 155-160.

Da Cunha A.B., Dobzhansky T.H., 1954. A further study of chromosomal polymorphism in Drosophila willistoni in its relation to the environment. Evolution, 8, 119-134.

Gonzalez A., 1985. Estudio de la estructura genética de dos poblaciones naturales de Drosophila melanogaster respecto a genes que afectan a la viabilidad. Thesis, Universidad Valencia.

Haldane J.B.S., 1956. Estimation of viabilities. J. Genet., 54, 294-296.

INOUE Y., 1979. The fate of polymorphic inversions of Drosophila melanogaster transferred to laboratory conditions. Jpn. J. Genet., 54, 83-86.

INOUE Y., WATANABE T.K., 1979. Inversion polymorphisms in Japanese natural populations of Drosophila melanogaster. Jpn. J. Genet., 54, 69-82.

Inoue Y., Watanabe T., Watanabe T.K., 1984. Evolutionary change of the chromosomal polymorphism in Drosophila melanogaster populations. Evolution, 38, 753-765.

KNiBb W.R., OAKeshotT J.G., Gibson J.B., 1981. Chromosome inversion polymorphisms in Drosophila melanogaster. I. Latitudinal clines and associations between inversions in Australasian populations. Genetics, 98, 833-847.

Kusakabe S., MukaI T., 1984. The genetic structure of natural populations of Drosophila melanogaster. XVII. A population carrying genetic variability explicable by the classical hypothesis. Genetics, 108, 393-408.

LEFEVRE G., 1976. A photographic representation and interpretation of the polytene chromosomes of Drosophila melanogaster salivary glands. In : Ashburner M., Novitski E. (ed.), The Genetics and Biology of Drosophila, Vol. 1a, 31-36. Academic Press, London.

Lindsley D.L., Grell E.H., 1972. Genetic variations of Drosophila melanogaster. Carnegie Inst. Wash. Publ. No 627.

McKenzie J.A., Parsons P.A., 1974. Microdifferentiation in a natural population of Drosophila melanogaster to alcohol in the environment. Genetics, 77, 385-394.

Metrler L.E., Voelker R.A., Mukai T., 1977. Inversion clines in populations of Drosophila melanogaster. Genetics, 87, 169-176.

Monclus M., Prevosti A., 1978-1979. Cellar habitat and Drosophila populations. Genética Ibérica, 30-31, 189-201.

Mukai T., Yamaguchi O., 1974. The genetic structure of natural populations of Drosophila melanogaster. XI. Genetic variability in a local population. Genetics, 76, 339-366.

NAJERA C., 1985. Variabilidad de mutaciones que afectan al color de los ojos en poblaciones naturales y experimentales de Drosophila melanogaster. Thesis Universidad Valencia.

PAIK Y.K., 1979. Inversion polymorphisms in wild populations of Drosophila melanogaster. Korean J. Genet., 1, 18-27.

StAl.Ker H.D., 1976. Chromosome studies in wild populations of Drosophila melanogaster. Genetics, 82, 323-347.

Stalker H.D., 1980. Chromosome studies in wild populations of Drosophila melanogaster. II. Relationship of inversion frequencies to latitude, season, wing-loading and flight activity. Genetics, 95, 211-233.

TAChida H., Mukai T., 1985. The genetic structure of natural populations of Drosophila melanogaster. XIX. Genotype-environment interaction in viability. Genetics, 111, 43-55.

Watanabe T.K., Watanabe T., 1973. Fertility genes in natural populations of Drosophila melanogaster. III. Superiority of inversion heterozygotes. Evolution, 27, 468-475.

Watanabe T.K., Yamaguchi O., Mukai T., 1976. The genetic variability of third chromosomes in a local population of Drosophila melanogaster. Genetics, 82, 63-82.

WATANABE T.K., YAMAKAKI T., 1976. Evidence for coadaptation: negative correlation between lethal genes and polymorphic inversions in Drosophila melanogaster. Genetics, 82, 697-702.

Zacharopoulou A., Pelecanos M., 1980. Seasonal and year-to-year inversion polymorphism in a southern Greek Drosophila melanogaster wild population. Genetica, 54, 105-111. 